\title{
REDUCING HANDOFFS BETWEEN SEQUENTIAL TRADES: A SIMULATION
}

\author{
Meng Wai Yaw' ${ }^{1}$, Zofia K. Rybkowski², and H. David Jeong ${ }^{3}$
}

\begin{abstract}
Trade specialization has created a significant number of handoffs on construction sites. Without proactive management from the general contractor, handoffs can result in the generation of waste, such as idle time between production activities, transport waste originating from an excessive number of mobilizations and demobilizations, and errors and omissions from miscommunication between trades. These interruptions can severely disrupt the workflow of a project. While small batching of activities offers opportunities for scheduling to takt time, a tension potentially exists between the desire for small batches and the benefits of reduced handoffs that accompany grouping of activities. This paper discusses the development of a lean simulation that explores the advantages of reducing the number of handoffs on a construction project while still acknowledging the benefits of small batching. A first run study of the simulation game was conducted on a sample of 30 students. Metrics showed all teams experienced a significant reduction in the number of turns to complete a round when several sequential tasks were grouped together. On site, this result may be achieved by employing a multi-skilled crew, sharing information more fully through Integrated Project Delivery (IPD), or by selective prefabrication. While feedback was positive, further work is needed to strengthen the game's learning outcomes.
\end{abstract}

\section{KEYWORDS}

Lean simulation, workflow, batch-size, handoff, takt

\section{INTRODUCTION}

In modern construction business environments, it is common for large building projects to involve numerous specialty contractors (Cuperus et al. 2010; Tommelein and Ballard 1997). Lehtonen-Wegelius (1998) has shown that up to $90 \%$ of a project's value can be subcontracted.

While the productivity of a particular activity may gain some level of efficiency from trade specialization with the use of highly skilled crews and specialized equipment/tools, this inherently creates a considerable number of handoffs between activities/trades (Walsh et al. 2003). Because there are no contractual agreements between subcontractors in conventional construction contracts, each subcontractor will only work within its

1 Graduate Student, Department of Construction Science, Texas A\&M University, College Station, TX 77843, USA, myaw2@tamu.edu, orcid.org/0000-0002-6191-0337

2 Associate Professor, Department of Construction Science, Texas A\&M University, College Station, TX 77843, USA, zrybkowski@gmail.com, orcid.org/0000-0002-0683-5004 (corresponding author)

3 Professor, Department of Construction Science, Texas A\&M University, College Station, TX 77843, USA, djeong@tamu.edu, orcid.org/0000-0003-4074-1869 
discipline and its assigned scope. As a result, parts instead of the whole are optimized on a site, where each subcontractor will arrange and schedule a crew for its own convenience and productivity, rather than for that of the general contractor (Walsh et al. 2003).

These handoffs, if not effectively managed by the general contractor, may not only severely impact the project workflow, they may also introduce a significant amount of waste into the process. This is demonstrated with the prevalence of time-gate phenomena observed by Bashford et al. (2002) in large-scale residential construction in the United States, where it was discovered that only $25 \%$ of elapsed working time was value-added time, with the remaining $75 \%$ constituting wait time (i.e., a type of waste) between activities. In fact, in a follow-up study, Walsh et al. (2003) claimed that a "next-day timegate robs the overall process of the gains implied by the specialization." Additionally, projects in which the general contractor acts only as a contract broker and leaves the coordination work to subcontractors, may lead to "an excessive number of RFIs submitted to raise the likelihood for change orders and thus extra pay to contractors, and also paper work building up to support litigation upon completion" (Tommelein and Ballard 1997).

The problems associated with handoffs are not only limited to wait time generated when a particular work zone switches from one trade to another, a high number of trades switching also creates an unnecessary amount of mobilization and demobilization effort for each trade. The "parades of trades" (Tommelein et al. 1999) in construction often requires certain disciplines such as the electricians to "return a couple of times, to run the wires through the conduits and then to mount the switches and power-points" (Cuperus et al. 2010). The issue is exacerbated when these trades are located relatively far away from the construction site. An excessive amount of transportation waste is created when a specific trade partner needs to travel back and forth between home office and job site multiple times. In cases where the construction site is located in urban centers, the likelihood of encountering traffic congestion may further increase the amount of idle (non-value adding) time between activities.

A simulation study performed by Antunes et al. (2010) found a proportional relationship between the percentage of transient time and flow variability of a process, prompting the researchers to highlight the importance of setup time reduction on projectdriven production flow. One method to minimize setup time, which has shown a proven track record of success in the manufacturing industry, is the Single Minute Exchange of Die (SMED). Developed by Japanese industrial engineer Shigeo Shingo, SMED dramatically reduces the time needed to change equipment, which enables the ability to only produce what is needed to pull to customer demand (Ohno 1988). The principle of SMED is to "convert as many changeover steps as possible to 'external' (performed while the equipment is running), and to simplify and streamline the remaining steps" (Vorne Industries n.d.). The concept of SMED has been sporadically applied in the construction industry. An example of SMED practices in construction is the use of prefabricated components or off-site construction (Gibb 1999). With the use of prefabricated components, certain building tasks are performed externally to the construction site, which reduces the number of on-site assembling activities.

\section{LEAN CONSTRUCTION AND FLOW}

Lean processes remove waste, add value, using continuous improvement, in a culture of respect for people; one intended outcome of these lean processes is perfect flow (Liker 2004; Rybkowski and Forbes 2016). Unlike a manufacturing assembly line where a product is transformed as it flows past stationary workers, on a construction site, workers 
move past stationary spaces as they transform those spaces. Despite this difference, the tenets are the same; lean construction practitioners are able to apply the fundamental principles of assembly line flow to construction processes.

A pioneer of lean construction, Koskela (1992) introduced the concept of flow to the construction industry, with his theory of transformation, flow, and value (TFV), referencing a new production philosophy that shared many characteristics with Lean Production. Ballard (2000) and Howell developed the Last Planner ${ }^{\mathrm{TM}}$ System of Production Control (LPS) to introduce flow to construction processes in an industry plagued by poor performance with respect to time, cost, and quality - the metaphorical iron triangle of construction management. Ballard and Howell had observed that one of the greatest frustrations for construction managers was the inability to accurately predict workflow; one trade partner could create significant delays, not only for workers who immediately followed, but for other downstream players who depended on a reliable schedule. By contrast, LPS stabilizes workflow by directly engaging those who complete the work to collaboratively develop the project schedule, thus ensuring that promises made by trade partners can be realistically achieved. Involving trade partners throughout the scheduling process also creates buy-in, and an accountability process known as PPC (Percent Planned Complete) heightens willingness to reliably deliver, thus mitigating a critical source of variability that interrupts workflows.

Line-of-Balance (LOB) scheduling, also called location-based or velocity scheduling, makes inefficiencies and conflicting work flows visually apparent (Kenley and Seppänen 2010). Like a Gantt or Bar Chart, an LOB marks time along the horizontal axis, but unlike a Gantt Chart, the vertical axis is used not only for listing activities, but for indicating the location of those activities as well — making rates visible by their slopes. Project managers using this method aspire to achieve parallel flows - a process that mimics the levels of efficiency observed on assembly lines where larger activities are broken into smaller component activities of approximately equal duration. The LOB plots in Figure 1 graphically demonstrate how hyper-specialization of trades and time-gates can result in vacant sites for much of a day, as well as an excessive number of time-consuming mobilizations and demobilizations, along with redundant setup and clean-up periods.

Takt time scheduling takes LOB to the tactical level, where workflows may be perceived as metaphorical wagons on a train of activities that moves to a beat (takt) through specified zones of approximately equal work density (Tommelein 2017). Taking inspiration from the "Parade Game," takt planning helps reduce variability commonly observed on traditionally delivered projects, increasing the reliability of planning with respect to time, cost, quality and safety (Tommelein et al. 1999). Lean philosophy prescribes that transformation of a product moving along a manufacturing assembly line should be done in small batch sizes, and that the product should be pulled to the beat of takt, as dictated by customer demand. However, on a construction site, where most work is completed by human beings moving between stationary locations, rather than by stationary machines operating on a moving product, a transitional period before and after an activity is often needed (Antunes et al. 2010). Unlike machines that can operate nonstop, human workers must go home to rest before returning to a job site. Human beings also require time to focus on a new task ("cognitive shifting"; Rogers and Monsell 1995).

This very real difference between human and mechanical actors creates tension between the call for small batches in lean manufacturing (resolved by SMED) and the reality in lean construction that there can be a considerable cost premium associated with small batches when human beings are involved. Also, although trade specialization does 
improve efficiency of activities, projects tend to fail at the intersection of contracts (Lichtig 2004).
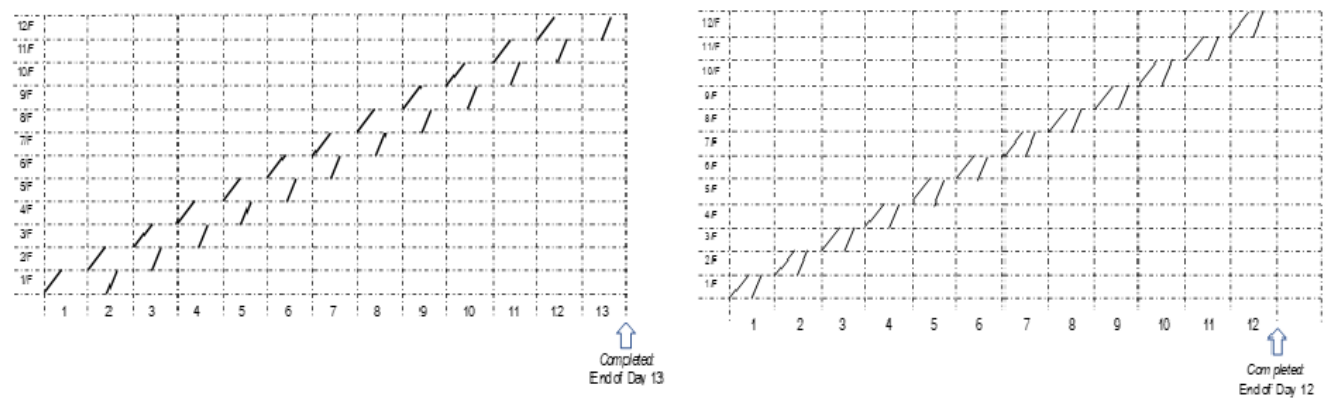

Figure 1: Line-of-Balance charts depicting workflows on 12-story high-rise building

(Left) Time-gating, where trades are allocated a single day per specialty tends, to increase project costs due to excessive mobilizations and demobilizations on site, errors and omissions from multiple handovers, and unnecessarily vacant job sites (Right) Multi-skilling between sequential tasks, for example, potentially offers opportunities for time and cost savings because more than one activity can be accomplished within a single day

With the silo-ization of specialties comes an increasing number of mobilizations, setup times, clean-up periods, and demobilizations, as well as potential for increased misunderstandings between trades, which can lead to errors. In fact, over-specialization on construction projects may neutralize or even worsen any efficiency gains the system was intended to provide. On the other hand, workers who have instead developed proficiency in at least two sequential activities (i.e. multi-skilled individuals) are sometimes called " $\pi$-shaped people" (Michels 2019); these individuals may perform a function similar to SMED in manufacturing, but for onsite construction.

\section{SIMULATION PROCESS}

The goal of this paper is to describe a simple lean simulation game developed by the authors to demonstrate how project workflow could be improved by reducing the number of handoffs between disciplines.

To play the game, the following are needed:

- One facilitator and at least three participants per suit of cards (up to 12 participants per card deck is possible)

- One deck of playing cards (minimum)

- Writing materials to record the results (e.g., pen, paper)

Before starting the game, a facilitator gives instructions orally to participants. Firstly, the participants are asked to form teams of 3 players each. While waiting for team formation, the facilitator separates a full deck of playing cards into four sets of 13 cards, according to suit (e.g., club, spade, heart, and diamond). Next, the facilitator shuffles each set of cards. During each round, a team will receive a set of playing cards of the same suit (A, $2,3,4, \ldots, 9,10, \mathrm{~J}, \mathrm{Q}$ and $\mathrm{K}$ ) and each player within a team is expected to obtain four to five cards in hand, that are in random order within a particular suit.

The game works as follows: 
1. In each round, the player who holds the Ace card will start the game by laying down the Ace card on the table.

2. The order of the cards being laid down must go sequentially from Ace to King (e.g., A, 2, 3, 4, 5, 6, 7, 8, 9, 10, J, Q, K). If the card being laid down is Ace, then the next card to be laid down must be "2", regardless of who is holding the "2" card.

3 . If the first player has the " 2 " card, then $s /$ he needs to lay down the " 2 " card on the table. If not, the player who holds the " 2 " card takes her/his turn.

4. In each turn, each player lays down the maximum number of consecutive cards in her/his hand. For example, if the first player happens to have Ace, " 2 " and " 3 " cards in her/his hand, then s/he can lay down all 3 cards at once before the player who holds the "4" card takes her/his turn.

5. To facilitate the data collection process, it is recommended to separate the card(s) laid down by each player. If a player can lay down only one card, then s/he leaves it on the table as it is, and the next player lay the subsequent card beside it. Do not stack card on top of each other. If a player gets to lay down more than one card, they should be stacked together, and the next card (by another player) should be laid down beside it.

6. The game continues until the "King" card is laid down.

7. The goal of the game is to lay down all the cards, in order, using the minimum number of turns.

8. Record the number of turns (i.e., player being switched). If step 5 is being followed, the number of turns will equal to the number of piles of cards.

\section{ROUND I}

Follow step 1 through 8 without any modifications. See Figure 2.

\section{ROUND II}

This round is similar to Round I except that an extra step is needed. Before the game starts (i.e., Step 1), each player is allowed to initiate a card swap once with another player in the team. The facilitator should not offer advice or suggestions to the teams on the swapping process. Instead, the facilitator can remind the participants about the goal of the game, which is to lay down all the cards, in order, using a minimum number of turns.

The swapping process is shown in Table 1. Note that although each player can only initiate one card swap, s/he can respond more than once to swapping request from other players on the team. Note there must be a mutually agreed exchange of cards between players. Each player should still have the same number of cards in hand after the swapping process. After the swapping process is completed, follow step 1 through 8 . Figure 3 illustrates the card swapping process in Round II.

\section{METRICS}

The purpose of Round I was to create a benchmark for improvements observed in Round II. Similar to all other lean simulation games, metrics are required to measure and quantify the performance of an improvement initiative (Rybkowski et al. 2012). The metric used for this lean simulation game is "number of handoffs." This is equal to the number of turns to lay down all the cards in a team. Note that there is a theoretical minimum and maximum value for this metric. The theoretical minimum will be 3 , which means that 
each player has perfect sequence of cards; whereas the theoretical maximum will be 13 , which means that only one card is being laid down in each turn. A fewer number of handoffs typically corresponds to better workflow.

Table 1: Swapping process during Round II

\begin{tabular}{cc}
\hline Player & Can swap with \\
\hline A & Either B or C \\
B & Either A or C \\
C & Either A or B \\
\hline
\end{tabular}
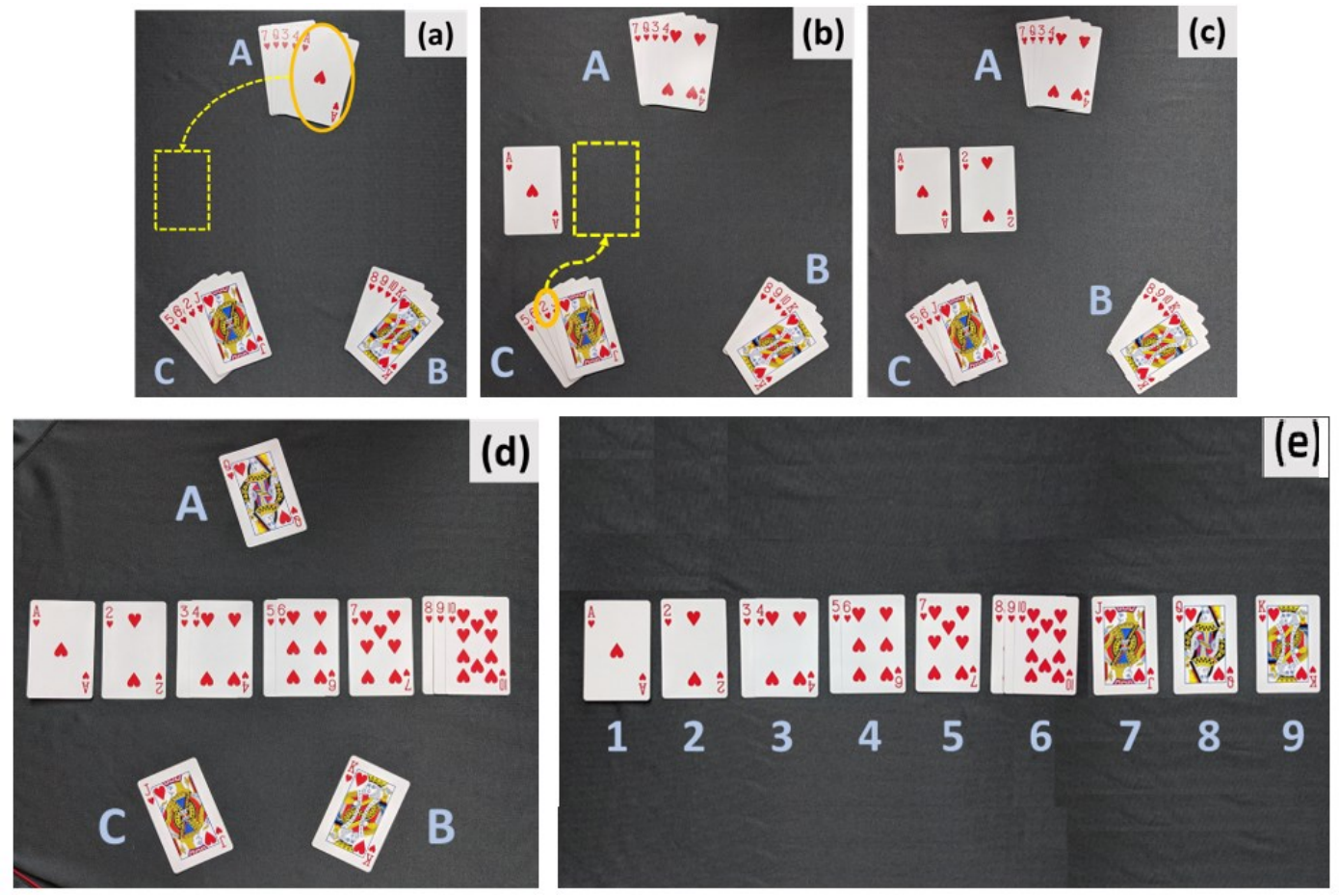

Figure 2: Snapshot overview of Round I

(a) Each player in a team receives four (or five) cards of the same suit, but in random order; (b) Player A starts the game because s/he has the Ace card; (c) Player C takes her/his turn because s/he has the "2" card. Since there is a switch in player, " 2 " card is placed beside Ace, and not with Ace; (d) The game continues by laying down the cards

in order. If a player has more than one consecutive card, the player can lay the consecutive cards together as a "clump". For example, Player B has "8", "9" and "10"

in her/his hand, so Player B can lay down these three cards together; (e) A round is complete when the King card has been laid. The number of turns will be the number of distinct piles of cards on the table (i.e., nine)

\section{SIMULATION FIRST RUN STUDY}

A first run study of this simulation game was conducted on January 16, 2020 with a sample of 30 graduate students from the College of Architecture at Texas A\&M 
University. The purpose of this first run study was to verify the effectiveness of this game in delivering its intended lessons.

To ensure consistency in conducting this simulation game in the future, the authors developed a facilitator's script specifically for this game, which contains verbatim instructions regarding game mechanics, metrics involved, and overall flow of the game. The facilitator's script was used to administer the first run study. In addition, a post-game, open-ended style questionnaire was created to collect anonymous feedback from participants in order to identify potential areas for improvement.


Figure 3: Snapshot overview of Round II

(a) Each player in a team receives four (or five) cards of the same suit, but in random order; (b) Player A trades the "10" card with Player B's "6" card; (c) Player B trades the

King card with Player C's Ace card; (d) Player C trades the "8" card with Player A's

Jack card; (e) Cards in each player's hand after the swapping process; (f) Game outcome after following step 1 through 8 . Number of turns as shown in figure is five.

A total of ten teams of three students participated in this first-run study. Figure 4 and 5 are photographs taken during the first run study. Table 2 shows the results of the first run study. All ten teams experienced a reduction in the number of turns in Round II, with most teams being able to achieve (or come close to) the theoretical minimum value of three turns. The average percentage reduction in the number of turns was $63 \%$.

A post-game questionnaire was distributed to each participant before $\mathrm{s} / \mathrm{he}$ was debriefed (i.e., immediately following completion of Round II). This was done to ensure the feedback collected would be free from any bias that might be introduced, and thus the true effectiveness of this game could be evaluated. 
When participants were asked what the number of turns in the game most likely represented, half of the responses ( 15 out of 30 ) collected were related to time (i.e., project duration or project schedule). According to one participant, the number of turns can be seen as analogous to the "amount of time someone has to return to workplace to continue her/his job". In addition, a respondent characterized each turn as a "discrete stretch of time for which one participant can work without interruption."

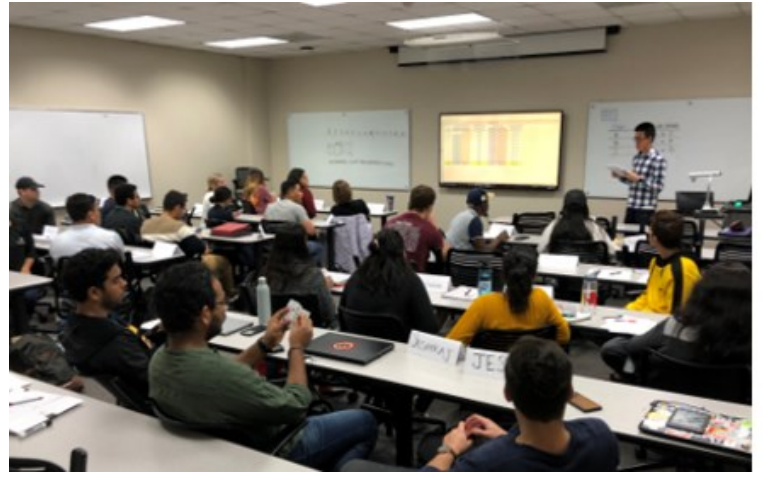

Figure 4: Facilitator explaining the simulation to participants

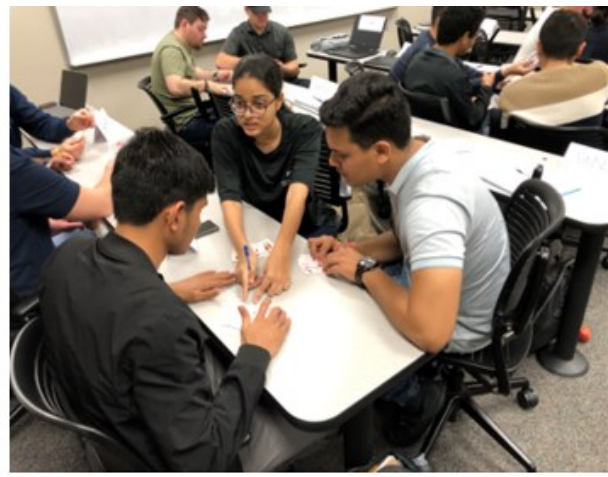

Figure 5: Participants discussing their card swapping strategies during Round II

A few themes could be identified from the participants' responses when they were asked about the main lesson(s) of the game. Half of the participants (15 out of 30) viewed communication and collaboration between team members, which were both enabled in the card swapping process during Round II, as key factors contributing to the reduction in number of handoffs during Round II. A few participants also felt the simulation highlighted the importance of proper project planning and scheduling. An optimized workflow results if the interfaces between trades can be minimized during planning. Another theme suggested by some of the participants was the impact of good management skills on project performance. Based on their responses, a good manager should align everyone's skill with an appropriate task, because any unused skill (or talent) is regarded as waste. Lastly, several participants reported that the simulation helped them to realize there can potentially be some time savings when project members start to learn from each other and understand the needs of other members. Efficiency gains can also be expected if multi-skilled crew/subcontractors are employed on a construction project.

\section{DISCUSSION}

This lean simulation game was designed to explore the benefits of reducing the number of handoffs on a construction project. The outcome of the first run study may be interpreted in a number of ways.

Firstly, handoffs can be minimized, for example, by hiring a multi-skilled crew capable of performing more than one consecutive task (i.e., sequential multi-skilling). Each card can be viewed as representing a specific skill required to complete the project. In Round I, the cards in each player's hand are random, hence each player is most likely to throw down a card (use her/his skill) one at a time (single-skilled). This simulates the hyper-specialization of trades. Because each trade only performs a minute portion of the project, more trades are required to complete the entire project, which results in more interfaces between trades. In Round II, players realized that, without receiving any advice from the facilitator, having a group of consecutive cards in hand is the key to completing the project in a fewer number of turns. This explains why participants instinctively traded 
their cards in such a way that each player held a maximum number of consecutive cards in her/his hands. Consequently, each player was able to throw down more than one card (a multi-skilled operation) during her/his turn. In other words, sequential task multiskilling may improve the flow of a project by reducing the number of changeovers between trades. This belief has been validated by a pilot study conducted by Cuperus et al. (2010). By using a multi-skilled team comprised of different subcontractors, the fitout time of a dwelling was reduced from 35 days to less than 20 days. According to the researchers, this significant improvement was partly due to the reduction in both the number of subcontractors involved and the number of decision-making points.

Table 2: First run study results

\begin{tabular}{|c|c|c|c|}
\hline \multirow[t]{2}{*}{ Teams } & \multicolumn{2}{|c|}{$\begin{array}{c}\text { Number of } \\
\text { Turns }\end{array}$} & \multirow{2}{*}{$\begin{array}{c}\% \text { difference } \\
\left(\frac{\text { Turns }_{I I}-\text { Turns }_{I}}{\text { Turns }_{I}} \times 100\right)\end{array}$} \\
\hline & $\begin{array}{c}\text { Round } \\
I\end{array}$ & $\begin{array}{c}\text { Round } \\
\text { II }\end{array}$ & \\
\hline 1 & 8 & 4 & -50 \\
\hline 2 & 12 & 3 & -75 \\
\hline 3 & 11 & 3 & -73 \\
\hline 4 & 11 & 4 & -64 \\
\hline 5 & 10 & 5 & -50 \\
\hline 6 & 12 & 5 & -58 \\
\hline 7 & 12 & 3 & -75 \\
\hline 8 & 11 & 4 & -64 \\
\hline 9 & 9 & 3 & -67 \\
\hline 10 & 11 & 5 & -55 \\
\hline Average & 10.70 & 3.90 & -63 \\
\hline
\end{tabular}

Alternatively, one could interpret that the number of handoffs in this simulation was reduced due to proper communication and collaboration of project participants and integration of work processes. Integrated Project Delivery (IPD) pursues the overall success of a project by contractually binding major project participants into one team under a single contract, from its earliest stages of delivery. Many lean design and construction methods such as Big Room meetings, Target Value Design, and the Last PlannerTM System of Production Control in an IPD project are used with the goal of achieving best value for the project overall. This relatively new contractual arrangement typically comes with profit sharing/risk sharing clauses which dramatically increase team collaboration and work process integration by breaking down barriers to information flow. Also, the scope of work for each project participant is not as rigidly defined as it is in more conventional (e.g., design-bid-build) project delivery processes. Depending upon the expertise of each participant and ideas generated - as shared and agreed by the entire team during the delivery - the allocated work tasks for each participant may increase or decrease if a change is determined to be the best for the project. This phenomenon is especially true if the project is still in its engineering and design stages. Thus, this simulation game may successfully represent a key value of IPD. For example, the clumping of consecutive cards in the simulation game could be viewed as a change of 
each project participants' work scope based on the entire project team's decision as the best for the project based on active communication and collaboration processes. What the grouping of consecutive cards implies when a project goes into the construction stage is that hiring an MEP contractor instead of recruiting separate contractors for mechanical, electrical and plumbing, respectively, will likely minimize waste and improve flow.

Lastly, this lean simulation carries the message that prefabrication can also provide a way to reduce the number of on-site assembly handoffs. In Round I, every trade is performed onsite, with minimal prefabricated components. In Round II, each cluster of consecutive cards may be interpreted as a prefabricated component. Instead of having separate flow of goods delivered to the site, prefabrication enables a "clustered flow of goods" (Smook et al. 1996) to be delivered to the site, which reduces the number of possible interferences and handoffs. For example, a general contractor may choose to use pre-cast concrete members in lieu of cast-in-place concrete. Because prefabrication usually takes place in a manufacturing-like environment and is handled by a single entity (i.e., the fabricator), the handoffs within the production process of a prefabricated component are more tightly controlled and coordinated.

The primary purpose of this lean simulation game is to illustrate how workflow on a construction project can be improved by reducing the number of handoffs. However, most participants in the first run study interpreted this simulation in a manner that differed from the authors' expectations. Instead of viewing the reduction in number of turns as a result of improved cohesiveness between adjacent trades, the majority of the participants attributed this improvement to the opportunity given in Round II to communicate, discuss and develop a strategy as a team. This is clearly indicated when words such as "collaboration," "communication," and "coordination" were mentioned by a substantial margin of participants, when they were asked to state what they thought were the main lessons of the game. In fact, for a company considering ways to improve handoffs, it may be worthwhile to use the opportunity to ask participants to brainstorm (and then capture on a flip chart or white board) specific ways to reduce handoffs (e.g. via multi-skilling, collaboration and integration, or prefabrication, for example). Facilitators are encouraged to use the game as a launch point for discussing the pros and cons of various methods.

Although the above-mentioned outcomes were not the lessons intended by the designers, the authors decided not to regard this simulation game as a failure since most participants in the first run study were able to learn something valuable during play. The game also received a considerable amount of positive feedback. Participants generally agreed that it was fun and interactive - particularly the card swapping process which allows players to think critically and to work together as a team toward a common goal.

The significance of cohesiveness between adjacent disciplines is the primary message that this game originally attempted to deliver. The construction workforce has been predominantly made up of single-skilled workers. Strict labor union rules and increasing project complexities have increased the demand for construction workers or professionals that have only a single expertise. While there are certainly circumstances that warrant the use of single-skilled workers, the proliferation of a single-skilled workforce has inadvertently created numerous disciplinary silos. Problems arise when all these specialists are required to work together on a common project. Trade specialization causes the number of interfaces (handoffs) between trades to increase significantly, which also greatly increases the chance of workflow being disrupted. Without proactive coordination from the general contractor, each specialty trade partner will perform its work in such a way that primarily maximizes its own business interests. This phenomenon of "throwing 
it over the wall" results in unnecessary time and money spent on correcting errors from handoffs between trades, further disrupting the project workflow.

This is the reason the authors recommend the industry to adopt various lean principles that can minimize the impact of handoffs on project workflow. The authors acknowledge that it is nearly impossible to eliminate all handoffs on a construction project; nonetheless, the project team should strive to coordinate, if not reduce, the number of handoffs on-site as much as possible. Three different methods have been proposed in this paper. A general contractor could choose to employ a multi-skilled crew capable of performing multiple consecutive tasks. The authors also propose collaboration and integration of project participants as a potential means to lessen the impact of the silo-ization of the specialties. Lastly, the use of prefabrication or off-site construction is also suggested as a way to reduce the number of on-site handoffs.

\section{CONCLUSION}

This paper reports on the development and testing of a lean simulation game that investigates reducing handoffs between trades as a way to improve workflow on a construction project. The authors used the game as a means to explore the potential tension existing between the desire for small batch sizes prescribed by Lean philosophy, while still recognizing the benefits of reduced handoffs that accompany grouping of consecutive activities. Based on results collected from a first run study, a reduction in number of turns was observed when efforts were made by participants to enhance cohesiveness between sequential tasks. Three different methods to reduce the number of handoffs were discussed in this paper, including: multi-skilling, collaboration through Integrated Project Delivery, and prefabrication. Although the game received positive feedback from participants as a first run study, further exploration will be necessary to improve the learning outcomes of this game.

\section{ACKNOWLEDGMENTS}

The authors would like to acknowledge the substantial contribution of former Texas A\&M graduate students towards the development of this simulation: Matthew Hueben and Trighunaa Ramineni.

\section{REFERENCES}

Antunes, R., González, V., and Walsh, K. 2010. "Quicker Reaction, Lower Variability: The Effect of Transient Time in Flow Variability of Project-Driven Production." Proc. $24^{\text {th }}$ Ann. Conf. Int. Group for Lean Constr., Boston, Mass., USA.

Ballard, G. 2000. "The last planner system of production control." PhD dissertation, University of Birmingham, Birmingham, UK.

Barlow, J., Cohen, M., and Jashapara, A. 1997. Towards Positive Partnering: Revealing the Realities in the Construction Industry. Bristol, UK: Policy Press.

Bashford, H., Sawhney, A., Mund, A., and Walsh, K. 2002. "Process mapping of residential foundation slab construction processes." Proc. Winter Simulation Conf., Vol. 2, 1752-1758. San Diego, CA.

Cuperus, Y., Wamelink, H., and Resodihardjo, G. 2010. "Reducing Fit-Out Time in a Netherlands Housing Project." Proc. 18 ${ }^{\text {th }}$ Ann. Conf. Int. Group for Lean Constr., Hafia, Israel, 326-333. 
Gibb, A.G.F. 1999. Off-site Fabrication: Prefabrication, Pre-assembly, and Modularisation. Scotland, UK: Whittles Publishing.

Howell, G.A. 1999. "What is Lean Construction-1999." Proc. $7^{\text {th }}$ Ann. Conf. Int. Group for Lean Constr., Berkeley, Calif., USA.

Kenley, R. and Seppänen, O. 2010. Location-Based Management for Construction: Planning, Scheduling and Control. London: Spon Press.

Koskela, L. 1992. Application of the new production philosophy to construction. Tech. Report No. 72, Ctr. for Integr. Facility Engin. (CIFE), Stanford Univ., Stanford, CA.

Lehtonen-Wegelius, T. 1998. "Improving subcontracting of the construction industry by participatory cooperation." Human Factors in Organizational Design and Management VI, Proc. $6^{\text {th }}$ Int. Symp. on Human Factors in Organizational Design and Management, The Netherlands, 69-74.

Lichtig, W.A. 2004. "The integrated agreement for lean project delivery." Construction Lawyer, 26(3), 1-8.

Liker, J.K. 2004. The Toyota Way: 14 Management Principles from the World's Greatest Manufacturer. New York: McGraw-Hill.

Michels, D. 2019. "Going Pi-Shaped: How to Prepare for Work of the Future." Forbes. $<$ https://www.forbes.com/sites/davidmichels/2019/09/27/going-pi-shaped-how-toprepare-for-the-work-of-the-future/\#552405f0647d $>$ (May 21, 2019).

Ohno, T. 1988. Toyota Production System: Beyond Large-Scale Production. Cambridge, MA: Productivity Press.

Rogers, R.D. and Monsell, S. 1995. "Costs of a predictable switch between simple cognitive tasks." J. of Experimental Psychology: General, 124(2), 207-231.

Rybkowski, Z. K. and Forbes, L. 2016. "Chapter 8: Lean Construction." In: Razzak Rumane, A. (ed.) Handbook of Construction Management: Scope, Schedule, and Cost Control, Boca Raton, FL: CRC Press Taylor \& Francis Group.

Rybkowski, Z., Zhou, X., Lavy, S., and Fernandez-Solis, J. (2012). "Investigation into the nature of productivity gains observed during the Airplane Game lean simulation." Lean Construction J., 78-90.

Smook, R.A.F., Melles, B., and Welling, D.T. 1996. "Co-Ordinating the Supply Chain Diffusing Lean Production in Construction." Proc. $4^{\text {th }}$ Ann. Conf. Int. Group for Lean Constr., Birmingham, UK.

Tommelein, I.D. 2017. "Collaborative Takt Time Planning of Non-Repetitive Work." Proc. $25^{\text {th }}$ Ann. Conf. Int. Group for Lean Constr., Heraklion, Greece, 745-752.

Tommelein, I.D. and Ballard, G. 1997. Coordinating Specialists. Technical Report, Construction Engineering and Management Program, Civil and Environmental Engineering Department, University of California, Berkeley.

Tommelein, I.D., Riley, D.R., and Howell, G.A. 1999. "Parade Game: Impact of Work Flow Variability on Trade Performance." J. Constr. Eng. Manage., 125(5) 304-310.

Vorne Industries. n.d. "SMED (Single-Minute Exchange of Dies)." Lean Production. $<$ https://www.leanproduction.com/smed.html $>$ (May 19, 2020).

Walsh, K. D., Sawhney, A., and Bashford, H.H. 2003. "Cycle-Time Contributions of Hyper-Specialization and Time-Gating Strategies in US Residential Construction." Proc. $11^{\text {th }}$ Ann. Conf. Int. Group for Lean Constr., Virginia, USA. 